\title{
Triorganotin(IV) Complexes of Schiff Base Derived from Glycine: Synthesis, Characteristic Spectral Studies and Antifungal Activity
}

\author{
ROBINA AMAN ${ }^{\mathrm{a}^{*}}$, GARIMA MATELA ${ }^{\mathrm{a}}$, \\ MANJU LATA UPADHYAY ${ }^{\mathrm{b}}$ and TRIPTI GANGWAR ${ }^{\mathrm{c}}$
}

${ }^{a}$ Department of Chemistry, Kumaun University, S.S.J.Campus Almora -263 601, India

${ }^{\mathrm{b}}$ Department of Botany, Kumaun University, S.S.J.Campus Almora -263 601, India

${ }^{\mathrm{c}}$ Department of Chemistry, A.N. College, Patna, Bihar-800013, India

amanrobina@yahoo.com

Received 14 August 2012 / Accepted 19 September 2012

\begin{abstract}
A series of triorganotin(IV) complexes of $N$-(2-hydroxy-1-naphthylidene) glycine (1), having general formula $\left[\mathrm{Ph}_{3} \mathrm{Sn}(\mathrm{Hhngl})\right]$ (2), $\left[\mathrm{Bu}_{3} \mathrm{Sn}(\mathrm{Hhngl})\right]$ (3), [ $\left.\mathrm{Me}_{3} \mathrm{Sn}(\mathrm{Hhngl})\right]$ (4), [where $\mathrm{H}_{2} \mathrm{hngl}=$ $\mathrm{N}$-(2-hydroxy-1-naphthylidene) glycine] were synthesized by reacting of triorganotin(IV) chloride with the ligand, with the aid of sodium iso-propoxide in appropriate stiochiometric ratios $(1: 1,1: 2)$. All the complexes exhibit good antifungal activity against four pathogenic fungi namely, Aspergillus niger, Aspergillus flavus, Penicillium sp. and Fusarium sp.
\end{abstract}

Keywords: Triorganotin complexes, Schiff base, Spectroscopic studies, Antifungal activity

\section{Introduction}

Organotin(IV) complexes show a spectrum of biological effects and have been extensively studied in various biological fields ${ }^{1-6}$. It is worth noting that, for a long time, organotin(IV) complexes have been widely used in a variety of industrial and beneficial use in agricultural applications $^{7-9}$.

The organotin(IV) complexes of Schiff bases have received notable attention in view of their structural chemistry and remarkable biological activities ${ }^{10-12}$. Regarding this, the conformation and geometry and biological activity of organotin(IV) complexes of Schiff bases have been investigated. In the present study, we have synthesized some triorganotin(IV) complexes as potential antifungal agents.

\section{Experimental}

All the reagents, viz., 2-hydroxy-1-naphthaldehyde (Aldrich), triphenyltin(IV) chloride (Merck), tributyltin(IV) chloride (Merck), trimethyltin(IV) chloride (Merck) were used as received. All the chemicals and solvents used, were dried and purified by standard methods, 
and moisture was excluded from the glass apparatus using $\mathrm{CaCl}_{2}$ drying tubes. The melting points were determined in open capillaries with electronic melting point apparatus. $\mathrm{C}, \mathrm{H}$ and $\mathrm{N}$ analysis of ligand and complexes were carried on a VarioEL, CHNS elemental analyzer. The tin content in the synthesized complexes were determined gravimetrically as $\mathrm{SnO}_{2}$. Infrared spectra of the solid compounds were recorded on a Perkin-Elmer 1600 series FT-IR spectrophotometer in the range $4000-500 \mathrm{~cm}^{-1}$ from $\mathrm{KBr}$ discs and 500-200 from CsI discs. ${ }^{1} \mathrm{H}$ NMR spectra were recorded on a Bruker Avance II 400 NMR spectrometer at SAIF, Punjab University, Chandigarh, India, using DMSO or $\mathrm{CDCl}_{3}$ as a solvent and TMS as the internal standard. Molecular weight determinations were carried out by the Rast camphor method. The Conductivity Measurement was performed using conductometer Eco Testr EC Low in DMSO having $10^{-3} \mathrm{M}$ at room temp. The antifungal activity of ligand and their diorganotin(IV) complexes were evaluated by poison food technique.

Synthesis of Schiff base (1)

Schiff bases were prepared by condensation of hot aqueous $(25 \mathrm{~mL})$ solution of glycine (0.975 g; $0.013 \mathrm{~mol}$ ) and 2-hydroxy-1-naphthaldehyde (2.238 g; $0.013 \mathrm{~mol})$, dissolved in ethanol $(50 \mathrm{~mL})$. The reaction mixture was refluxed for about $2 \mathrm{~h}$ (Scheme I) and yellow brown polycrystalline precipitate was obtained after standing overnight. It was purified by repeated washing with aqueous-ethanol (1: 2) and dried in vacuum over fused $\mathrm{CaCl}_{2}$.

\section{Synthesis of complexes}

\section{[Ph ${ }_{3} \mathrm{Sn}($ Hhngl)] (2)}

The solution of triphenyltin(IV) isopropoxide (2.045 g, $0.005 \mathrm{~mol}$ ) and $\mathrm{H}_{2} \mathrm{hngl}$ (1.031 g, $0.0045 \mathrm{~mol}$ ) was stirred for half an hour and then refluxed on a wax bath for 8-10 h. The isopropanol liberated, was removed azeotropically with benzene and the product was dried under reduced pressure. The oily product thus obtained was solidified and purified by trituration with petroleum ether (b.p. $60-80{ }^{\circ} \mathrm{C}$ ).

\section{$\left[\mathrm{Bu}_{3} \mathrm{Sn}(\mathrm{Hhngl})\right]$ (3)}

Complex 3 was prepared in the similar way as complex 2. Tributyltin(IV) isopropoxide (1.745 g, 0.005 mole) and $\mathrm{H}_{2} \mathrm{hngl}$ (1.031 g, 0.0045 mole).

\section{$\left[\mathrm{Me}_{3} \mathrm{Sn}(\mathrm{Hhngl})\right]$ (4)}

Complex 4 was prepared in the similar way as complex 2 Trimethyltin(IV) isopropoxide (1.115 g, 0.005 mole) and $\mathrm{H}_{2}$ hngl (1.031 g, 0.0045 mole).

\section{Results and Discussion}

The Schiff base was prepared by adopting earlier reported method (Scheme 1$)^{13}$. A new methodology has been used to synthesized triorganotin(IV) complexes. Organotin complexes were usually prepared by reacting organotin hydroxide or organotin oxide to corresponding ligand and also by reacting organotin halide to sodium or potassium salt of ligand. In present study, we have replaced halogen of triorganotin with isopropoxide group by reacting them to sodium isopropoxide (Scheme 2). The triorganotin isopropoxides were isolated and reacted to ligand. These reactions proceed with the liberation of isopropanol, which is fractionated out azeotropically and estimated to monitor the completion of reaction. Owing to highly hydroscopic nature of the triorganotin(IV) alkoxides, all the reactions would be carried out under strictly anhydrous condition. The structure of complexes was confirmed by their physiochemical analysis such as elemental, azeotropic, gravimetric analysis and conductivity measurement. The precise information about their structure is obtained from IR and ${ }^{1} \mathrm{H}$ NMR spectral measurements. 
<smiles>CC[C@@H]([13CH]=NCC(=O)O)c1cccc2c(C=NCC(=O)O)c(O)ccc12</smiles>

Scheme 1

$$
\mathrm{R}_{3} \mathrm{SnCl}+\mathrm{NaOPri} \underset{\text { Reflux }}{\stackrel{\text { Benzene }}{\longrightarrow}} \mathrm{R}_{3} \mathrm{Sn}(\mathrm{OPri})+\mathrm{NaCl}
$$

( $\mathrm{R}=\mathrm{Me}, \mathrm{Bu}$ and $\mathrm{Ph} ; \mathrm{NaOPr}^{i}=$ sodium isopropoxide)

$$
\mathrm{R}_{3} \mathrm{Sn}(\mathrm{OPri})+\mathrm{H}_{2} \mathrm{hngl} \stackrel{\text { Benzene/Toluene }}{\text { 1: }_{1} / \text { Reflux }}
$$

\section{Elemental analysis}

\section{Scheme 2}

Experimental and calculated elemental compositions of the complexes are given in Table 1. The analytical data are in good agreement with the proposed stoichiometry of the complexes.

\begin{tabular}{|c|c|c|c|c|c|c|c|c|c|}
\hline \multirow{2}{*}{$\begin{array}{c}\dot{0} \\
\dot{z}\end{array}$} & \multirow{2}{*}{$\begin{array}{l}\text { Ligand/ } \\
\text { Complexes }\end{array}$} & \multirow{2}{*}{ 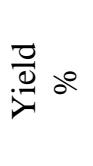 } & \multirow{2}{*}{ Colour } & \multirow{2}{*}{${ }^{\mathrm{M} . P .}$} & \multicolumn{4}{|c|}{$\begin{array}{l}\text { Elemental Analysis \% } \\
\text { Obsd. (Calcd.) }\end{array}$} & \multirow{2}{*}{$\begin{array}{c}\text { Molar } \\
\text { Conductivity, } \\
\mu \mathrm{S} \mathrm{cm}^{-1}\end{array}$} \\
\hline & & & & & C & $\mathrm{H}$ & $\mathrm{N}$ & Sn & \\
\hline 1 & $\mathrm{H}_{2} \mathrm{hngl}$ & 72 & Yellow & 65 & $\begin{array}{c}68.44 \\
(68.12)\end{array}$ & $\begin{array}{c}4.84 \\
(4.80)\end{array}$ & $\begin{array}{c}5.89 \\
(6.11)\end{array}$ & & \\
\hline 3 & $\begin{array}{c}{\left[\mathrm{Ph}_{3} \mathrm{Sn}(\mathrm{H}\right.} \\
\text { hngl) }]\end{array}$ & 71 & Green & $>300$ & $\begin{array}{c}64.37 \\
(64.33)\end{array}$ & $\begin{array}{c}4.38 \\
(4.32)\end{array}$ & $\begin{array}{c}2.37 \\
(2.42)\end{array}$ & $\begin{array}{c}20.58 \\
(20.52)\end{array}$ & 16 \\
\hline 4 & $\begin{array}{c}{\left[\mathrm{Bu}_{3} \mathrm{Sn}(\mathrm{H}\right.} \\
\mathrm{hngl})]\end{array}$ & 76 & $\begin{array}{l}\text { Dark } \\
\text { Brown }\end{array}$ & $>300$ & $\begin{array}{c}57.88 \\
(57.92)\end{array}$ & $\begin{array}{c}7.14 \\
(7.17)\end{array}$ & $\begin{array}{c}2.70 \\
(2.66)\end{array}$ & $\begin{array}{c}22.90 \\
(22.94)\end{array}$ & 06 \\
\hline 5 & $\begin{array}{l}{\left[\mathrm{Me}_{3} \mathrm{Sn}(\mathrm{H}\right.} \\
\text { hngl)] }\end{array}$ & 78 & Green & $>300$ & $\begin{array}{c}48.98 \\
(49.01)\end{array}$ & $\begin{array}{c}4.85 \\
(4.87)\end{array}$ & $\begin{array}{c}3.57 \\
(3.54)\end{array}$ & $\begin{array}{c}30.28 \\
(30.32)\end{array}$ & 06 \\
\hline
\end{tabular}

Table 1. Analytical details of the various tin- and organotin(IV) complexes of $\mathrm{N}$-(2hydroxy-1-naphthylidene) glycine

\section{Molar conductance}

Molar conductance of the synthesized complexes showed very low values indicating their non-electrolytic nature ${ }^{14}$.

\section{Infrared spectra}

The characteristic infrared frequencies of the triorganotin(IV) complexes are given in Table 2. The IR spectra of the triorganotin complexes display a broad vibrational band at $3400-3413 \mathrm{~cm}^{-1}$ which is assignable ${ }^{15-16}$, to the unbonded $-\mathrm{OH}$ stretching of the phenolic group. 
Table 2. IR spectral data of ligand and triorganotin(IV) complexes of $N$-(2-hydroxy-1 naphthylidene) glycine (in $\mathrm{cm}^{-1}$ )

\begin{tabular}{|c|c|c|c|c|c|c|c|c|c|}
\hline$\sum_{\dot{0}}^{\dot{0}}$ & $\begin{array}{l}\text { Ligand/ } \\
\text { Complexes }\end{array}$ & $v(\mathrm{OH})$ & 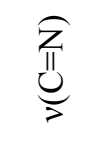 & 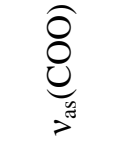 & $\underbrace{\stackrel{0}{0}}_{\underbrace{\infty}}$ & $z$ & $\begin{array}{l}\underset{0}{1} \\
\stackrel{\tilde{n}}{=}\end{array}$ & $\underbrace{Z}_{>}$ & $\begin{array}{l}-v_{\text {as }}(\mathrm{Sn}-\mathrm{C}) \\
\mathcal{f}_{1} / \mathrm{v}_{\mathrm{s}}(\mathrm{Sn}-\mathrm{C})\end{array}$ \\
\hline 1 & $\mathrm{H}_{2} \mathrm{hngl}$ & $\begin{array}{c}3500- \\
2300 \mathrm{br}\end{array}$ & & $1640 v s$ & $1397 \mathrm{~s}$ & & & & \\
\hline 2 & {$\left[\mathrm{Ph}_{3} \mathrm{Sn}(\right.$ Hhngl)] } & $3411 \mathrm{br}$ & $1607 \mathrm{~s}$ & $1642 s$ & $1400 \mathrm{~m}$ & 242 & $524 \mathrm{~m}$ & $418 m$ & $\begin{array}{l}278 \mathrm{~s}, \\
245 \mathrm{~s}, \\
226 \mathrm{~s}\end{array}$ \\
\hline 3 & {$\left[\mathrm{Bu}_{3} \mathrm{Sn}\right.$ (Hhngl)] } & $3413 b r$ & $1590 s$ & $1637 \mathrm{vs}$ & $1408 \mathrm{~m}$ & 229 & $549 \mathrm{~m} *$ & $413 w$ & $549 m^{*}$ \\
\hline 4 & {$\left[\mathrm{Me}_{3} \mathrm{Sn}(\right.$ Hhngl)] } & 3400br & $1590 s$ & $1636 v s$ & $1394 m$ & 242 & $501 w$ & $467 w$ & $\begin{array}{l}528 w, \\
487 m\end{array}$ \\
\hline
\end{tabular}

s: strong; m: medium; w: weak; br: broad; *merge

These complexes give a strong asymmetric stretching frequencies $v_{\mathrm{as}}(\mathrm{COO})$ near 1636$1642 \mathrm{~cm}^{-1}$ and a weaker symmetrical stretching frequencies $v_{\mathrm{s}}(\mathrm{COO})$ near $1394-1408 \mathrm{~cm}^{-1}$. The magnitude of $v_{\mathrm{as}^{-}} v_{\mathrm{s}}(\Delta v)$ separation has been used to explain the type of boding of carboxylate group to the tin metal ${ }^{17}$. The magnitude of $v_{\mathrm{as}}{ }^{-} v_{\mathrm{s}}(\Delta v)$ for these complexes are above $200 \mathrm{~cm}^{-1}$, indicating the monodentate bonding of the carboxylate group to the tin metal. In triorganotin(IV) complexes, $v(\mathrm{C}=\mathrm{N})$ band, display between $1590-1607 \mathrm{~cm}^{-1}$, is considerably shifted towards lower frequencies with respect to that of the free Schiff base (around $1620 \mathrm{~cm}^{-1}$ ), indicating the coordination of the azomethine nitrogen to the triorganotin(IV) moiety.

The bonding of the carboxylate group to the tin metal is further confirmed by the appearance of a band at 501-549 $\mathrm{cm}^{-1}$, assignable to the Sn-O stretching frequency ${ }^{18}$. In the lower frequency region, the band observed in the region $413-467$ has been assigned to the $v \mathrm{Sn} \leftarrow \mathrm{N}$ vibration ${ }^{19-22}$. The far IR spectra of triphenyltin(IV) complex shows bands at $278 \mathrm{~cm}^{-1}$ and at $226 \mathrm{~cm}^{-1}$, which may be assigned ${ }^{23}$ to the $v_{\mathrm{as}}(\mathrm{Sn}-\mathrm{C})$ and $v_{\mathrm{s}}(\mathrm{Sn}-\mathrm{C})$, respectively, whereas the corresponding peaks at $528 \mathrm{~cm}^{-1}$ and at $487 \mathrm{~cm}^{-1}$, have also been ${ }^{23}$ assigned in the spectra of trimethyltin(IV) complex. In the case of tributyltin(IV) complex the appearance of $v(\mathrm{Sn}-\mathrm{C})$ bands are not certain due to the overlapping of Sn-O stretching vibration.

\section{${ }^{1} \mathrm{H}$ NMR spectra}

Table 3 shows the chemical shifts ( $\delta$ in ppm) of various protons in metal complexes. The appearance of a signal at $\delta 9.40-10.81 \mathrm{ppm}$, in the complexes, may be due to the unbonded phenolic -OH proton ${ }^{24}$. The ${ }^{1} \mathrm{H}$ NMR spectra of the complexes, the signals in the region $\delta$ 8.34-9.10 ppm have been assigned to azomethine $(-\mathrm{N}=\mathrm{CH}-)$ proton ${ }^{21,24}$. The multiplet between $\delta 7.02-8.34 \mathrm{ppm}$ is assigned to the naphthylidene group protons. The butyl protons attached to the tin in tributyltin(IV) complex observed at appropriate position in accordance to the previously reported values 21,25 . In the triphenyltin(IV) complex, the signals for the phenyl groups attached to tin are observed in the range of $\delta 7.14-8.00 \mathrm{ppm}$, in conjugation with naphthylidene group protons. Two signals due to $\mathrm{Sn}-\mathrm{Me}_{3}$ in trimethyltin(IV) complex are observed around $\delta 0.83 \mathrm{ppm}$ and $\delta 0.64 \mathrm{ppm}^{4,26}$, indicating the presence of methyl groups in two different environment. In the light of above finding, the proposed structure of triorganotin(IV) complexes are shown in Figure 1. 
Table 3. ${ }^{1} \mathrm{H}$ NMR Spectral data of ligand and triorganotin(IV) complexes of $N$-(2-hydroxy1-naphthylidene) glycine (in $\delta \mathrm{ppm}$ )

\begin{tabular}{|c|c|c|c|c|c|}
\hline S.No. & $\begin{array}{l}\text { Ligand/ } \\
\text { Complexes }\end{array}$ & $\begin{array}{l}\text { Ar-OH } \\
\text { proton }\end{array}$ & $\begin{array}{l}-\mathrm{N}=\mathrm{CH}- \\
\text { proton }\end{array}$ & $\begin{array}{c}\text { Ar-H } \\
\text { protons }\end{array}$ & $\begin{array}{l}\mathrm{Sn}_{-} \mathrm{C}_{4} \mathrm{H}_{9}, \mathrm{Sn}-\mathrm{CH}_{3}, \\
\text { Sn- } \mathrm{C}_{6} \mathrm{H}_{5} \text { protons }\end{array}$ \\
\hline 1 & $\mathrm{H}_{2} \mathrm{hngl}$ & $\begin{array}{c}10.79 \\
(\mathrm{~s}, 1 \mathrm{H})\end{array}$ & $8.60(\mathrm{~s}, 1 \mathrm{H})$ & $\begin{array}{c}7.11-8.34 \\
(\mathrm{~m}, 6 \mathrm{H})\end{array}$ & \\
\hline 2 & {$\left[\mathrm{Ph}_{3} \mathrm{Sn}\right.$ (Hhngl)] } & $\begin{array}{l}9.40 \\
(\mathrm{~s}, 1 \mathrm{H})\end{array}$ & $8.34(\mathrm{~s}, 1 \mathrm{H})$ & $\begin{array}{c}7.14-8.00 \\
(\mathrm{~m}, 6 \mathrm{H})\end{array}$ & $7.14-8.00(\mathrm{~m}, 15 \mathrm{H})$ \\
\hline 3 & {$\left[\mathrm{Bu}_{3} \mathrm{Sn}(\mathrm{Hhngl})\right]$} & $\begin{array}{l}10.70 \\
(\mathrm{~s}, 1 \mathrm{H})\end{array}$ & $9.10(\mathrm{~d}, 1 \mathrm{H})$ & $\begin{array}{c}7.02-7.88 \\
(\mathrm{~m}, 6 \mathrm{H})\end{array}$ & $\begin{array}{c}0.80,1.24 \text { and } \\
1.40-172(\mathrm{t}, \mathrm{tq} \text { and } \\
\left.\mathrm{m}, 27 \mathrm{H}, \mathrm{Sn}-\mathrm{C}_{4} \mathrm{H}_{9}\right)\end{array}$ \\
\hline 4 & {$\left[\mathrm{Me}_{3} \mathrm{Sn}(\right.$ Hhngl)] } & $\begin{array}{c}10.81 \\
(\mathrm{~s}, 1 \mathrm{H})\end{array}$ & $8.36(\mathrm{~d}, 1 \mathrm{H})$ & $\begin{array}{c}7.13-8.34 \\
(\mathrm{~m}, 6 \mathrm{H})\end{array}$ & $\begin{array}{c}0.87(\mathrm{~s}, 3 \mathrm{H}) \\
0.66(\mathrm{~s}, 3 \mathrm{H})\end{array}$ \\
\hline
\end{tabular}

s: singlet; d: doublet; t: triplet: m: multiplet
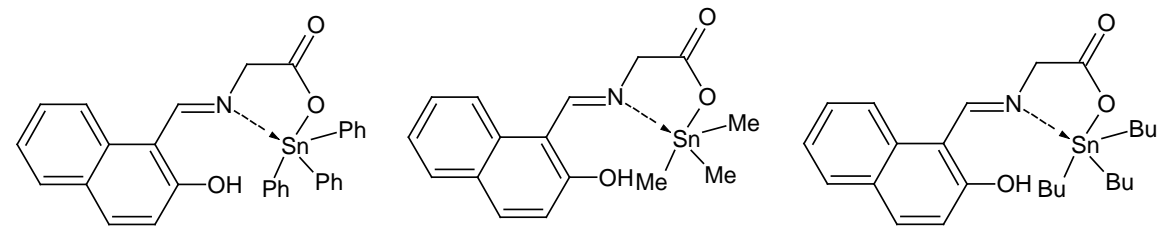

Figure 1. Proposed structure of triorganotin(IV) complexes

\section{Biological activity}

The antifungal activity of liand triorganotin(IV) complexes were evaluated by poisoned food technique $^{27-28}$. All these triorganotin(IV) complexes possessed antifungal activity against Aspergillus niger, Aspergillus flavus and Penicillium sp. as shown in Table 4.

Table 4. Antifungal bioassay results ${ }^{\mathrm{a}}$ (in vitro) for triorganotin(IV) complexes of $\mathrm{N}$-(2hydroxy-1-naphthylidene) glycine

\begin{tabular}{cccccc}
\hline \multirow{2}{*}{ S.No. } & Complexes & \multicolumn{4}{c}{ Mycelial growth inhibition, \% } \\
\cline { 3 - 6 } & $\begin{array}{c}\text { Aspergillus } \\
\text { niger }\end{array}$ & $\begin{array}{c}\text { Aspergillus } \\
\text { flavus }\end{array}$ & $\begin{array}{c}\text { Penicillium } \\
\text { sp. }\end{array}$ & $\begin{array}{c}\text { Fusarium } \\
\text { sp. }\end{array}$ \\
\hline 1 & {$\left[\mathrm{Ph}_{3} \mathrm{Sn}(\mathrm{Hhngl})\right]$} & 58.5 & 62.1 & 60.2 & 52.4 \\
2 & {$\left[\mathrm{Bu}_{3} \mathrm{Sn}(\mathrm{Hhngl})\right]$} & 49.2 & 46.7 & 52.1 & 48.6 \\
3 & {$\left[\mathrm{Me}_{3} \mathrm{Sn}(\mathrm{Hhngl})\right]$} & 52.5 & 50.1 & 55.3 & 50.1 \\
\hline
\end{tabular}

${ }^{\mathrm{a}}$ Concentration used $2.00 \mathrm{mg} \mathrm{ml}^{-1}$ of DMSO

The complex namely, $\left[\mathrm{Ph}_{3} \mathrm{Sn}\right.$ (Hhngl)] (2), showed more than $60 \%$ inhibition of mycelial growth against Aspergillus flavus and Penicillium sp. The complex [ $\left.\mathrm{Bu}_{3} \mathrm{Sn}(\mathrm{Hhngl})\right]$ (3) and [ $\left.\mathrm{Me}_{3} \mathrm{Sn}(\mathrm{Hhngl})\right]$ (4) showed maximum fungicidal activity against Penicillium sp. A perusal of tables 4 shows that the triphenyltin(IV) complex, exhibit maximum fungitoxicity than tributyl- and trimethyltin(IV) complexes of $\mathrm{H}_{2} \mathrm{hngl}$.

\section{Conclusion}

Based on various studies such as elemental analysis, IR and ${ }^{1} \mathrm{H}$ NMR spectral studies, fivecoordinate geometry for triorganotin(IV) complexes are proposed. The triorganotin(IV) complexes show good antifungal activity and the order of antifungal activity of triorganotin(IV) complexes of $\mathrm{H}_{2} \mathrm{hngl}$ is $\mathrm{Ph}>\mathrm{Me}>\mathrm{Bu}$. 


\section{Acknowledgement}

One of the authors (R.A.) thanks the U-COST, Dehradun, UK, for financial support in the form of a Research Project and another of the authors (G.M.) for the award of Project Fellowship under the same project.

\section{References}

1. Koch B, Baul T S B and Chatterjee A, J Appl Toxicol., 2008, 28(4), 430-438.

2. Molloy K C and Hartley F, Bioorganotin compounds The Chemistry of Metal Carbon Bond, vol. 5, Willey, New York, 1989, Chapter 11.

3. Sun M L, Ruan B F, Zhang Q, Liu Z D, Li S L, Wu J Y, Jin B K, Yang J X, Zhang S Y and Tian Y P, J Organomet Chem., 2011, 696, 3180.

4. Demertzi D K, Dokorou V, Primikiri A, Vargas R, Silvestru C, Russo U and Demertzis M A, J Inorg Biochem., 2009, 103(5), 738-744.

5. Ruiz S G, Torres J C, Prashar S, Fajardo M, Zizak Z, Juranic Z D and Kaluderovic G N, J Organomet Chem., 2011, 696, 3206

6. Prasad K S, Kumar L S, Prasad M and Revanasiddappa H D, Bioinorg Chem Appl., 2010; DOI: 10.1155/2010/854514.

7. Davies A G and Smith P J, Tin in comprehensive organometallic chemistry (eds) G Wilkinson, F G A Stone and E W Abel (Oxford: Pergamon Press), 1982, 2, 519.

8. Smith P J, Chemistry of tin (London: Blackie Academic and Professional) $2^{\text {nd }}$ Edn., 1997.

9. Li M X, Zhang D, Zhang L Z, Niu J Y and Ji B S, J Organomet Chem., 2011, 696, 852.

10. Baul T S B, Masharing C, Willem R, Biesemans M, Holcapek M, Jirasko R and Linden A, J Organomet Chem., 2005, 690, 3080-3094.

11. Baul T S B, Masharing C, Basu S, Rivarola E, Holcapek M, Ji-rasko R, Lycka A and Vos De D and Linden A, J Organomet Chem., 2006, 691, 952-965.

12. Handong Y, Hong M, Haolong X, Gao Z, Li G and Wang D, Eur J Inorg Chem., 2005, 22, 4572-4581.

13. Singh M K, Bhaumik S and Lal R A, J Indian Chem Soc., 2007, 84, 418-426.

14. Jamil K, Wajid R, Bakhtiar M and Danish M, J Iran Chem Soc., 2010, 7(2), 495-499.

15. Singh M, Synt React Inorg Met-Org Chem., 1985, 15, 235.

16. Abdellah M A, Hadjikakou S K, Hadjiliadis N, Kubicki M, Bakas T, Kourkoumelis N, Simos Y V, Karkabounas S, Barsan M M and Butler I S, Bioinorg Chem Appl., 2009, DOI:10.1155/2009/542979.

17. Ho B Y K and Zuckerman J J, Inorg Chem., 1973, 12, 1552.

18. Nath M and Yadav R, Bull Chem Soc Jpn., 1997, 70, 1331.

19. Nath M, Sharma C L and Sharma N, Synt React Inorg Met-Org Chem., 1991, 21, 807.

20. Singh HL, Singh JB, Int J Inorg Chem., 2012; doi:10.1155/2012/568797.

21. Nath M, Yadav R, Gielen M, Dalil H, Vos de D and Eng G, Appl Organomet Chem., 1997, 11, 727-736.

22. Singh H L and Varshney A K, Bioinorg Chem Appl., 2006; DOI:10.1155/BCA/2006/23245.

23. Nath M, Pokharia S and Yadav R, Coord Chem Rev., 2001, 215, 99-149.

24. Pettinari C, Marchetti F, Pettinari R, Martini D, Drozdov A and Troyanov S, Inorg Chim Acta, 2001, 325, 103-144.

25. Shahzadi S, Shahid K, Ali S and Bakhtiar M, Turk J Chem., 2008, 32, 333.

26. Azadmeher A, Amini M M, Hadipour N, Khavasi H R, Fun H K and Chen C J, Appl Organometal Chem., 2008, 22, 19.

27. Prakash O, Aneja D K, Hussain K, Lohan P, Ranjan P, Arora S, Sharma C and Aneja K R, Eur J Med Chem., 2011, 46(10), 5065-5073.

28. Burtamani Al- SKS, Fatope M O, Marwah R G, Onifade A K and Saidi Al- S H, $J$ Ethnopharm., 2005, 96, 107-112. 